\title{
DETERMINING HOWTO DO PROGNOSTICS, AND THEN DETERMINING WHAT TO DO WITH IT
}

\author{
Dr. Frank L. Greitzer, Pacific Northwest National Laboratory, 509372 4251, \\ frank.greitzer@pnl.gov \\ Cody J. Hostick, Pacific Northwest National Laboratory, 509375 4317, cody.hostick@pnl.gov \\ Russel E. Rhoads, Pacific Northwest National Laboratory, 509372 4355, russ.rhoads@pnl.gov \\ Dr. Miranda Keeney, US Army Logistics Integration Agency, 717770 7600, \\ miranda.keeney@hqda.army.mil
}

\begin{abstract}
Understanding how to do prognostics is rapidly evolving, but an area of study that is in its infancy is the development of doctrine regarding what to do with prognostic information. The US Army's Logistics Integration Agency has initiated a program to accelerate development and fielding of the hardware, information systems and business processes needed to seamlessly generate, transmit and use real-time, platform-based readiness data. This program is investigating how future logistics support concepts need to be adapted to fully exploit such data. This paper describes an approach that has been adopted by this program to facilitate the development of proactive business practices and logistics system architectures.
\end{abstract}

Keywords: prognostics, US Army, cost/benefit, user requirements, operational architecture, logistics footprint

\section{Introduction}

Prognostics is the process of predicting the future state of a system. Prognostics systems comprise sensors, a data acquisition system, and microprocessor-based software to perform sensor fusion, analysis, and reporting/interpreting of results with little or no human intervention, in real time or near real time. The US Army intends to make extensive use of prognostics technology on weapons platforms, support vehicles and even munitions. The Army Transformation is driving this move toward embedded prognostics. The Chief of Staff of the Army has initiated the Army Transformation to bring about fundamental changes in the Army's structure, equipment and doctrine. These changes are needed to align the Army with radically different mission requirements. A new Army Vision has been established to create a fighting force that achieves victory through superior striking speed, agility and mobility rather than massed power. This level of responsiveness is enabled by information and communication technologies that provide all echelons of the fighting force with real-time situation awareness and rapid reaction capabilities. The ability to react much more rapidly than the enemy is one of the keys to achieving a decisive victory across the full spectrum of operations. Another key 
Army Transformation goal is to reduce the logistics footprint in order to enhance the sustainability, deployability, readiness and reliability of military systems.

Dramatic changes in logistics processes are needed to support the new force. These new processes must be focused on the weapons systems, and must be readiness-driven, lean, and agile. They must detect and correct problems early, allocate resources where they are most needed, and continuously drive cost and labor out of the system. One of the key enablers for the objective sustainment processes envisioned here is to equip platforms with self-reporting, realtime, embedded prognostics and diagnostics systems. These systems contribute directly to several key objectives for the future Army:

- Virtual logistics situational awareness at all levels

- Proactive (rather than reactive) combat logistics

- Improved readiness for weapons platforms and support equipment

- Reduced logistics footprint on the battlefield

- More effective fleet management and reduced life cycle costs.

Putting prognostics capability onto equipment and developing the infrastructure needed to generate maximum benefit from the prognostics data represent major challenges. The Army has thousands of pieces of equipment that must eventually have these capabilities. Obviously they can't all be equipped all at once. The infrastructure needed to transmit, store and use the data is complex, requiring changes to many existing and emerging communications and information systems. The Army must have an implementation strategy that achieves maximum benefit with the resources available, recognizing that the technology is still evolving. Fundamental questions that must be addressed to develop an effective strategy are:

- When, where and how much prognostics capability should be developed and installed?

- How much of the data that is currently being collected would support prognostics? What additional data must be acquired on military platforms to support prognostics?

- Who can make use of the prognostics data, how do we get it to them and what tools do they need to use the data to carry out their tasks?

With technical assistance from Pacific Northwest National Laboratory (PNNL), the US Army Logistics Integration Agency (USALIA) has been addressing these issues for several years. They have been assessing the state-of-the-art in prognostics technology, extending the capabilities of the technology, examining implementation approaches and identifying changes to policies, doctrine, information systems and business processes required to get maximum benefit to the Army from prognostics data. This paper provides an overview of the results from several of these USALIA-sponsored efforts. 


\section{Deciding How to Implement Prognostics}

It will take many years and substantial investments to implement fully the Army's vision for self-reporting weapons platforms and support vehicles with embedded diagnostics and prognostics capabilities. The Army is taking a cost/benefit approach to tackle the question of which platforms get how much capability in what time frame. The results of early cost/benefit analyses are being used to help develop implementation strategies. More detailed analyses later on will tackle the questions of the optimum level of prognostics capability for a specific platform and the most cost-effective way to implement it.

The Army's cost/benefit analysis (CBA) approach considers development, procurement and operating and maintenance costs and both monetary and non-monetary benefits [1]. Nonmonetary benefits include creating tactical advantage for troops in combat situations, improving the readiness of combat forces and reducing the amount of logistics support required on the battlefield. Monetary benefits include near-term reductions in operations and support costs and reductions in the life-cycle costs of owning and operating a platform. Near-term cost reductions might result from things like reduction of collateral damage from catastrophic failure of components, reduction in the number of maintenance actions that replace good parts as the result of misdiagnosis, and reduced customer wait time resulting from anticipatory maintenance actions that ensure that parts, tools and personnel are in the pipeline at the earliest possible time. Life cycle cost reductions might result from reduced overhaul costs, extending the time between overhauls, and extending the life of components by reducing operator-induced failures.

Decision rules for applying the results of the CBA are not hard and fast. In general, an option with a high return on investment (ROI) and high non-monetary benefits would be implemented as soon as possible. For options with high ROI and modest non-monetary benefits, a recommended path forward would be to harvest "low-hanging fruit" to create cost savings that could be used to invest in additional implementation activities. If the ROI is modest and the nonmonetary benefit is high, the path forward might be to pursue the opportunity aggressively with available funds. Programs that are contemplated that have a low ROI and low non-monetary benefit should be abandoned. Table 1 provides a summary of likely actions the Army would take based on the possible outcomes from a CBA.

\section{Table 1. Action Matrix for CBA Results}

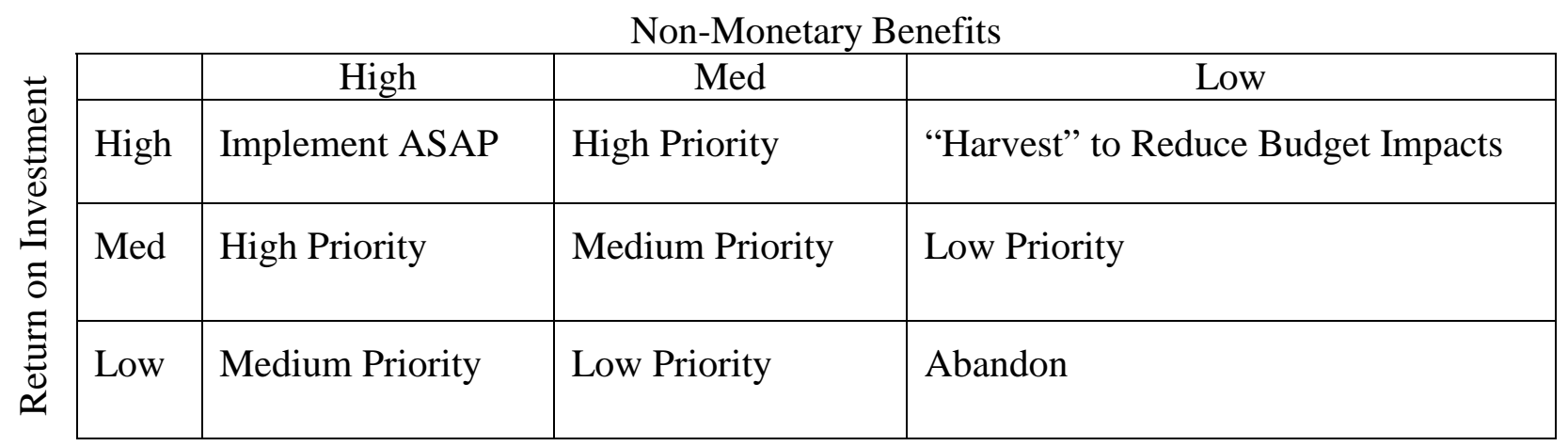


The Pacific Northwest National Laboratory (PNNL) has performed several preliminary CBA assessments for the USALIA. The results are being used to guide development of a prognostics implementation strategy. Early work has focused on drive-train components, since they tend to be major cost drivers and the technology for embedded prognostics is maturing rapidly. The results of these efforts are reviewed below.

\subsection{Cost/Benefit of Turbine Engine Prognostics on the M1 Tank}

As part of a 1998 project funded by the US Army Logistics Integration Agency, PNNL conducted an initial CBA assessment to aid in decisions about whether or not to develop a prototype prognostics system for the AGT1500 gas turbine engine on the M1 Abrams Tank. This system, originally called TEDANN (Turbine Engine Diagnostics using Artificial Neural Networks), would comprise (a) a set of sensors mounted to the turbine engine, (b) electronics for collecting and processing sensor signals, and (c) a microprocessor running artificial neural networks, rule-based algorithms, and statistical prediction analyses. This system, installed onboard the vehicle, senses and records engine operational status and performs diagnosis and prognosis of the engine's condition.

The CBA was performed to determine the scope of analysis; to define a cost-effective auxiliary sensor set to install on the engine to achieve a prognostics capability; and to quantify overall costs and anticipated benefits associated with development and deployment of such a system.

The analysis was conducted in accordance with guidelines published by the U.S. Department of the Army [1]. It also complied with guidelines published by the U.S. Congressional Report Service [2] for use by federal agencies in preparing economic analyses. Several potential deployment options were considered in determining the effect of incorporating prognostics functionality into the engine controller for the AGT1500 engine. For example, different collections of sensors were evaluated based on the value of the data provided by the candidate sensors and the cost and ease of installation of the sensors. Present costs for maintenance and repairs on Abrams tanks were obtained from various sources, including General Accounting Office [3] publications, Department of the Army Center for Economic Analysis and Cost (CEAC), and from discussions with the engine manufacturer, TACOM and end users. Costs for development and implementation of the prognostics system were estimated based on prototype development costs for an early prototype version of TEDANN, information gained from the National Guard, and data obtained from the engine manufacturer.

Anticipated system benefits from development and deployment of the prognostics system were determined by quantifying expected cost savings from avoided overhauls, avoided catastrophic failures, and decreased overhaul costs on a per tank basis. These calculations were based on conservative assumptions as to present costs for maintenance and overhauls and applied to the approximately 3600 M1 Abrams tanks expected to be in service between 2002 (when a prognostics system would be expected to be fielded) and 2030.

The results of the analysis indicated that development and deployment of an engine prognostics system with approximately a dozen auxiliary sensors (thermodynamic and vibration sensors installed via a wiring harness) would result in a benefit-to-cost ratio of about 11:1. This estimate 
is in general agreement with outcomes of similar analyses. For example, a CBA conducted for an expert systems-based engine monitoring system for helicopter gas turbine engines resulted in a ROI of about 12:1 [4].

Since the 1998 analysis, the USALIA and PM Abrams supported the development of an onboard prognostics system prototype that derived from the initial TEDANN work [5]. Called the REDIPRO (Real time Engine Diagnostics-Prognostics) system, this onboard prototype system was developed and given limited field-testing. Results of some of this testing are reported by Greitzer and Ferryman [6]. While no rigorous cost savings data have been collected to enable an assessment of the assumptions made in the initial CBA, the development costs have been in line with expectations. In fact, if deployed, REDI-PRO would certainly become a component of upgraded onboard systems (such as a new engine controller). Incorporation of this functionality into onboard systems would reduce the costs of deployment and yield an even more favorable ROI.

At the present time, the possible integration of the REDI-PRO onboard prognostics capability into the M1 Abrams tank is very much uncertain. Because of plans to replace the AGT1500 engine with a new engine (LV100), the expense of upgrading the old engine is an obstacle, despite the fact that the old engines are expected to remain in active status for at least another ten years. Therefore, the path forward for integrating prognostics into the M1 Abrams platform appears to be most promising for the new engine. Nevertheless, major obstacles still must be overcome in convincing decision makers that embedded prognostics will significantly impact operational and life-cycle costs. A 1999 paper [7] described the challenges and opportunities in developing and applying prognostics, and the need for logistics/maintenance organizations to change their business models in order to capitalize on prognostics. This discussion led to the creation of the USALIA's Weapon System Support Platform-based Readiness (WSSPR) program, which has as one goal the aim of characterizing the impact of embedded prognostics on the logistics/maintenance footprint and costs.

\subsection{Cost/Benefit of Drive Train Prognostics on the IAV}

A cost-benefit analysis was conducted for USALIA by PNNL to determine the economic feasibility of developing or enhancing diagnostics and prognostics systems for the US Army's Interim Armored Vehicle (IAV). For the purposes of this analysis it was assumed that the IAV will be based on the GM Defense/ General Dynamics Land Systems LAV III (Light Armored Vehicle III) platform. The LAV III is a lightly armored 8-wheeled vehicle powered by an electronically controlled Caterpillar diesel engine.

The analysis provided information on a total of 20 options for additional diagnostic/prognostic capabilities, including onsite oil analysis capability. Potential enhancements were considered for both maintenance facilities and vehicles. These options were compared to the base case of no additional diagnostic/prognostic capabilities beyond those currently available from the engine and transmission electronic control modules and associated maintenance facility support equipment. 
To determine where diagnostics or prognostics system upgrades may be of benefit in reducing cost of ownership for the IAV fleet, we gathered operational and maintenance data on other military vehicles powered by diesel engines, and have reviewed best industrial practices in terms of design, use and maintenance of diesel engines and automatic transmissions in heavy-duty applications. Maintenance information and cost data from a fleet of 32 LAV II vehicles being demonstrated at Ft. Lewis Washington and from other diesel powered military tactical vehicles provided a baseline for the cost benefit analysis.

For those options that would increase reliability, we conducted analyses to determine if they would be economically viable in terms of return on investment over the planned lifetime of the platform. For possible onboard enhancements, we considered the addition of sensors to the engine to improve diagnostic and prognostic capability. Additional onboard software-only options were also considered. As possible enhancements for the maintenance support facilities, we considered additional software and hardware for the facility-based Caterpillar "Electronic Technician" and Allison "Pro-Link" diagnostics systems. These options included onsite maintenance facility enhancements such as machine fluid analysis, which could be associated with the maintenance support equipment for the Caterpillar engines and Allison electronic transmissions.

Results indicated that additional onboard sensors to support engine and transmission prognostics would probably not be cost effective, provided that best commercial practices are incorporated into the design, operation and maintenance of the electronically controlled power pack components from Allison and Caterpillar. One possible exception in the case of onboard sensors is the installation of an inexpensive dielectric constant indicator to monitor crankcase oil deterioration. In addition, the following enhancements to the maintenance infrastructure for the IAV would increase reliability and appear to be cost effective:

- Use of onsite machine fluid analysis systems for near real-time determination of machine fluid condition and wear rates for implementation of true condition-based maintenance.

- Incorporation of prognostics capability into the software currently used to read codes and perform engine and transmission diagnostics based on data from the respective electronic control modules.

Addition of onsite oil analysis to the maintenance support system for the IAV was deemed cost effective in terms of direct and indirect tangible benefits. Analysis indicated that the current dollar return on investment for onsite oil analysis equipment is approximately 6.6:1 over 30 years. Successful transfer of primary oil analysis from AOAP to the field maintenance facilities will require acquisition of automated portable oil analysis equipment that is low cost, accurate, reliable, easy to use, and has small logistics footprint (automated operation, small size, low power requirements, no consumables). These calculated economic advantages for onsite oil analysis relate only to use of the oil analysis systems with the IAV. Use of the oil analysis systems with other Army machinery and equipment could further reduce overall maintenance costs. 
The option of developing advanced prognostics software for the IAV diesel engine and incorporating it into the engine's support system was estimated to yield a return on investment of 5.8:1 over 30 years.

Based on these findings and analyses, the report recommended that:

- Onsite machine fluid analysis capabilities should be provided for facilities supporting the IAV. The exact form of this support should be the subject of a small pilot program.

- An inexpensive dielectric constant oil analysis sensor should be evaluated for possible use as an on-board indicator of oil deterioration. These sensors are commercially available.

- Prognostics algorithms should be incorporated into the diagnostics software used for download and analysis of ECM/ECU data and code information. Such software may reside on the engine ECM or on the maintenance facility support equipment, or both.

\subsection{Prognostic Implementation Strategy for Legacy Diesel-Powered Vehicles}

Although a cost-benefit analysis has not been conducted for the US Army legacy diesel-powered fleet, the results of a qualitative assessment indicate that the potential economic benefits of applying best commercial diagnostics and prognostics practices to the US Army's legacy diesel fleet are enormous. Failure rates and maintenance costs collected by the U.S. Army Materiel Systems Analysis Activity (AMSAA) in support of war reserve planning shows tremendous differences between commercial and military equipment performance. A comparison of military versus commercial diesel engine life for different applications is shown graphically in Figure 1. Note the dramatic difference between in-service military equipment with minimal diagnostics and prognostics, and existing commercial equipment. The average life expectancy of the older in-service military diesels shown in Figure 1 is 1,430 hours. The average diesel life expectancy for commercial applications shown in Figure 1 is 14,750 hours (a ten-fold difference).

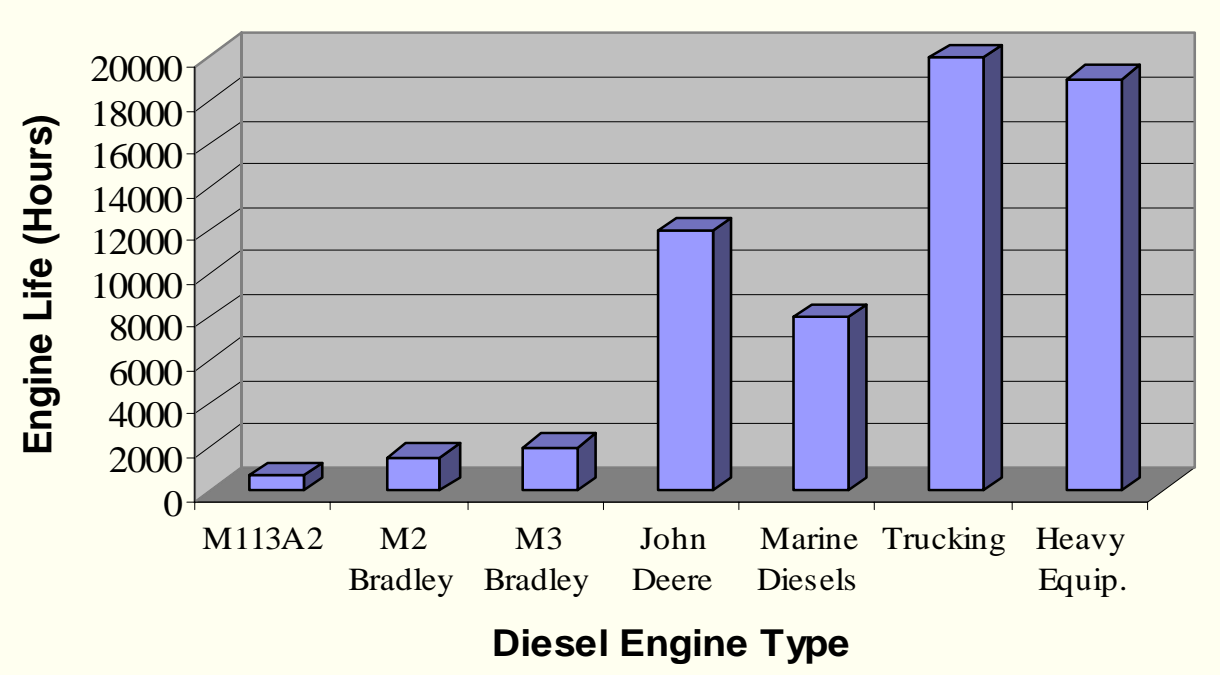

Figure 1. Comparison of Diesel Engine Lifetimes for Military and Commercial Applications 
The comparison between commercial and military diesel engine performance in heavy duty applications indicates a much longer engine lifetime for commercial diesel engines than for military diesels. Part of this difference is undoubtedly due to the difference in duty cycles between commercial and military applications. However, even if the entire difference were due to differences in duty cycle, this strongly suggests that military engines are not properly designed to tolerate the stressors associated with military vehicle applications, or not properly maintained, or both. Both equipment design and maintenance practices benefit significantly from proper application of diagnostic and prognostic technology. For example, the commercial sector will add extensive sensor suites to new vehicles to isolate and identify physical stressors that need to be eliminated through engineering redesign. Similarly, maintenance practices are improved through embedded diagnostics that both warn the operator of problems as well as actively limiting equipment operation to avoid catastrophic failure.

The approximately 174,000 diesel vehicles that make up the U.S. Army's legacy fleet vary substantially in development in regards to diagnostic and prognostic technology adoption, as represented by Figure 2 (the engine is used for illustrative purpose, the overall development cycle applies to all major vehicle components).

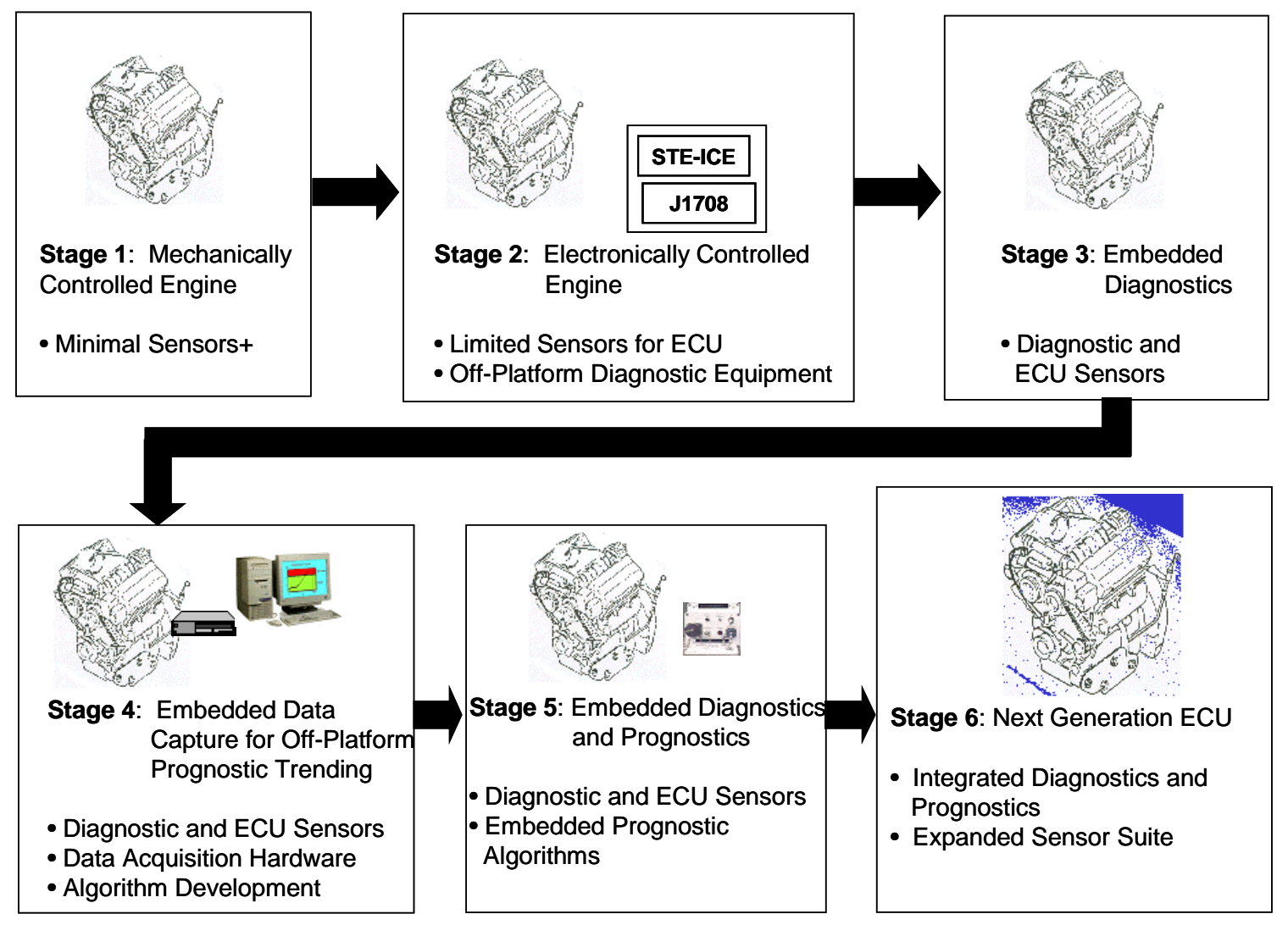

Figure 2. Engine Diagnostic and Prognostic Development Cycle 
The current legacy fleet is primarily in Stages 1 and 2 of Figure 2. The IAV acquisition represents Stage 3 technology. The ongoing Army Diagnostic Improvement Program (ADIP) and related efforts represent Stage 4 technology development. "Add-on" embedded systems are represented by Stage 5, leading to the right level of diagnostic and prognostic technology incorporated by materiel developers in replacement systems (Stage 6), which have not yet been pursued. There are multiple advantages of embedding diagnostic and prognostics on the vehicle (Stage 5 in Figure 2). This stage of development consisting of real-time data acquisition and analysis on the platform eliminates the need for off-platform sensor data communication, which is either periodic if completed by manual computer downloads, or bandwidth-limited if completed by tactical communication systems.

For any given vehicle, there are limited opportunities for the U.S. Army to insert diagnostic and prognostic technology. This is due to the infrequent nature of vehicle upgrades, LineReplaceable Unit (LRU) modifications, re-capitalization initiatives, etc. In the past, the U.S. Army has missed opportunities to leverage equipment modification and upgrades that would help close the performance gap between military and commercial systems. In the future, it will be key for the U.S. Army to be able to specify in detail the "right" level of embedded diagnostics and prognostics on new acquisitions/re-capitalization programs to enhance the sustainability, deployability, readiness and reliability of military systems.

\section{Maximizing the Benefits from Prognostics Data}

The Army's Vision for its future fighting forces is based on moving accurate information through the command and control systems in near real-time. The end-state objective is to move most logistics information without soldier input. Embedded diagnostics and prognostics capabilities are key to making the battlefield command and control systems work as envisioned.

The capability of a system to monitor its own health and logistics status and self-report this information can be leveraged to support other Army objectives such as enhanced readiness and readiness reporting, rapid deployment, reduced workload on soldiers, minimized logistics infrastructure on the battlefield, and lower life cycle costs. Determining how to maximize the benefits from embedded prognostics is a significant challenge. Platform-based readiness information will be used to support both tactical and sustainment decisions and analysis activities. Users requirements vary widely in the level of detail and timeliness of the information. Tactical commanders and logistics support units normally need only a few pieces of critical information - fuel status, ammo status and maintenance needs, but they need this information in near real-time. Personnel who manage the platform through its entire life cycle are more concerned with maximizing availability while reducing operations and maintenance costs. They need detailed information about operating and maintenance history and platform configuration changes. Their need for this information is not time-critical, however. Delays of days or even weeks are acceptable between the time the information is generated and when it is available to them [7]. The USALIA has initiated the Weapons System Support, Platform-Base readiness (WSSPR) program to examine these user requirements and develop an operating concept and the associated information systems/communications/business process architecture needed to provide all users with access to the data they need. 
Table 2 summarizes the high-level requirements identified by the WSSPR program, organized by the potential customers or beneficiaries of the proposed capabilities. WSSPR capabilities are identified that offer solutions to these requirements. The WSSPR operating concept described below shows how these capabilities would be implemented.

Table 2 WSSPR Requirements and Capabilities

\begin{tabular}{|c|c|c|}
\hline Customer & Requirement & WSSPR Capability \\
\hline Operators & Reduce Crew Workload & Automated Data Capture \\
\hline $\begin{array}{l}\text { Operational } \\
\text { Commanders }\end{array}$ & $\begin{array}{l}\text { Real-Time Readiness } \\
\text { Reporting }\end{array}$ & Automated Situation Reporting \\
\hline $\begin{array}{l}\text { Forward } \\
\text { Support } \\
\text { Battalion }\end{array}$ & $\begin{array}{l}\text { Keep Forces Ready to } \\
\text { Fight }\end{array}$ & $\begin{array}{l}\text { Real-time Data Enables Anticipatory Resupply and } \\
\text { Repair Actions }\end{array}$ \\
\hline $\begin{array}{l}\text { Combat } \\
\text { Repair Teams }\end{array}$ & Minimize Repair Times & $\begin{array}{l}\text { Mechanic Receives Failure Mode Info Prior to } \\
\text { Dispatch } \\
\text { Prognostics Identifies Problems Before Failure } \\
\text { Onboard Diagnostics Interface With Electronic } \\
\text { Tech Manual to Reduce Diagnostic Time }\end{array}$ \\
\hline $\begin{array}{l}\text { Rear-Area } \\
\text { Logistics } \\
\text { Providers }\end{array}$ & $\begin{array}{l}\text { Reduce Logistics } \\
\text { Equipment Needed on } \\
\text { the Battlefield }\end{array}$ & $\begin{array}{l}\text { Tailored Repair Parts Inventories } \\
\text { Embedded diagnostics and prognostics eliminates } \\
\text { test equipment } \\
\text { Real-time reporting of fuel, ammo, and repair part } \\
\text { usage }\end{array}$ \\
\hline $\begin{array}{l}\text { Platform Life } \\
\text { Cycle } \\
\text { Manager }\end{array}$ & Reduce Life Cycle Cost & $\begin{array}{l}\text { Provide Ability To Combine Failure Data With } \\
\text { Component Operating History And Identify Root } \\
\text { Cause Of Problems } \\
\text { Ability to Associate Platform Data with } \\
\text { Corresponding Data from Other Sources }\end{array}$ \\
\hline $\begin{array}{l}\text { Materiel } \\
\text { Managers }\end{array}$ & $\begin{array}{l}\text { JIT Inventory } \\
\text { Management }\end{array}$ & $\begin{array}{l}\text { Accurate Parts Usage Data and Predicted } \\
\text { Remaining Life of Hi-Value Items }\end{array}$ \\
\hline $\begin{array}{l}\text { National } \\
\text { Maintenance } \\
\text { Manager }\end{array}$ & $\begin{array}{l}\text { Accurate Forecasts of } \\
\text { Depot Workload and } \\
\text { Cost }\end{array}$ & $\begin{array}{l}\text { Accurate Data on Failure Modes and Predicted } \\
\text { Remaining Life of Hi-Value Repairable } \\
\text { Components }\end{array}$ \\
\hline $\begin{array}{l}\text { Depot } \\
\text { Maintenance } \\
\text { Provider }\end{array}$ & $\begin{array}{l}\text { Reduce Cost And } \\
\text { Improve Quality Of } \\
\text { Depot Repairs }\end{array}$ & $\begin{array}{l}\text { Provide Component-Specific Failure Data And } \\
\text { Operating History For Hi-Value Repairables }\end{array}$ \\
\hline $\begin{array}{l}\text { Doctrine } \\
\text { Developers }\end{array}$ & $\begin{array}{l}\text { Continuous } \\
\text { Improvement Of } \\
\text { Logistics Doctrine And } \\
\text { Training }\end{array}$ & $\begin{array}{l}\text { Ability to Access Detailed Data On Performance Of } \\
\text { The Logistics System }\end{array}$ \\
\hline
\end{tabular}


A preliminary WSSPR operating concept has been developed to provide a roadmap for maximizing the benefit to the Army from platform-based data. The WSSPR operating concept starts at the weapon system platform with a real-time diagnostic/prognostic capability. The primary function of this system is to monitor the health of the platform and predict when mission-critical components on that platform will require maintenance actions. The diagnostics and prognostics system also generates a detailed operating history of each component it monitors. This operating history is stored in onboard memory for later use by mechanics, or by engineers or other analysts in the wholesale logistics system.

Tactical commanders use platform-based readiness data to make decisions about deploying combat assets to respond to changing conditions in the combat zone. Because the tactical commanders have real-time information on fuel, ammo and health status of the platforms, they can optimize the use of their combat resources. The officers in charge of logistics support use this information to monitor the allocation of logistics assets and to re-direct logistics resources as priorities change. Real-time logistical situational awareness data from self-reporting platforms allows decision makers to meet the highest priority needs first, as well as enabling them to prevent logistical problems through the application of anticipatory supply and maintenance support. Logistics vehicles are also equipped with embedded diagnostics, prognostics and communications systems, permitting real-time tracking of the status of these assets.

Under the WSSPR concept, an electronic aid interacts with the embedded prognostic system to assist the crew in performing Preventive Maintenance Checks and Services (PMCS). The embedded system "populates" the data fields that can be filled with sensor information or diagnostic and prognostic results, only requiring the operator to provide information when a human observation or verification of information is necessary. The Interactive PMCS guides the crew through any procedures with which they were not familiar and automatically orders parts for upcoming routine maintenance actions. In garrison, the Interactive PMCS provides the pathway off the platform for routine readiness reporting information. The health status information would be passed from the embedded system to the palm-top computer. The palmtop computer would pass the information to higher-level logistics information systems.

Embedded diagnostics and prognostics equipment provide the capability to develop and maintain detailed operating and maintenance histories for platforms and the components on the platform that are major cost drivers. Once the information is moved off the platform into a logistics database, life cycle managers can use it to determine the root cause of excessive failures. For the first time, analysts will be able to characterize failures by OPTEMPO (tempo of operations), RPM-hour, loading, operator, mechanic and other important factors that can impact reliability. The results of these enhanced physics-of-failure and ultra-reliability analyses can be used to institute engineering changes, procedure modifications or training activities to reduce total ownership cost. Materiel mangers can use information from embedded prognostics to more accurately predict future demand for repair parts. This eliminates excess inventory and enables Just-in-Time inventory management. The National Maintenance Manager can use this information to more accurately predict depot overhaul requirements and more efficiently manage the workload of the depot maintenance provider. The depot mechanics will have access to operating history information and sensor information that will enable them to quickly identify 
the required repairs. Removal of the component before catastrophic failure eliminates collateral damage.

The expected operational impact of having access to real-time platform-based readiness data will include accurate, real-time readiness reporting; major reductions in battlefield repair times; less unscheduled maintenance; major reductions in dependent failures; reduced sustainment costs through Just-In-Time inventory management; product improvement investments that address real root cause of problems encountered in the field; smaller logistics footprint; and shorter deployment times. Most requirements for data entry by soldiers will be eliminated. Logistics data will be more accurate as well as more current.

\section{$4 \quad$ Next Steps}

Increasingly, economic considerations do not allow owners to replace equipment in their aging fleets, and thus there is pressure to extend the life of equipment well beyond the initially expected life. This is true for many kinds of complex mechanical systems including military tanks, aircraft, ships, locomotives, and heavy earth-moving equipment. Today the focus is on high-value systems. As technology is advanced to reduce size, weight and cost, and increase reliability of prognostics systems, the applications will migrate to more plentiful, lower-value systems with potential for greater cost savings.

To extend the life of complex mechanical systems and to reduce operational/life cycle costs, solutions must be found to reduce or eliminate premature failures and associated collateral damage, as well as to reduce or eliminate the down time that results from an inefficient maintenance/resupply process. Private industry and the military are realizing that maintenance/logistics systems must factor in the cost of "wait time" or "down time." This will increase emphasis on predictive maintenance-where parts, tools, and personnel are scheduled to be at the right place and at the right time to effect repairs. This requires real-time, onboard prognostics systems that monitor the health of equipment and are able to diagnose degradations in performance and predict faults, so that appropriate upkeep may be scheduled. This contributes to enhanced situational awareness, reduced logistics footprint, lower sustainment costs and increased readiness.

Equally important, capitalizing on prognostics information from self-reporting platforms requires that organizations be responsive to the prognostics information. For most organizations, achieving this proactive status amounts to a major transition that needs to be planned and managed. This will require workforce planning, training, scheduling and deployment to meet the new needs of the organization. Logistics, maintenance, procurement, and acquisition systems must be re-engineered for proactive operations. Doctrine, operating concepts, and business practices to support applications of platform-based data are not yet mature. There are many efforts underway across the Army that contribute to the objective of real-time, self-reporting platforms with embedded diagnostics and prognostics. While there is some level of coordination among these efforts, they are not all working toward a common vision of the future of Army logistics. A major objective of the WSSPR Program is to coordinate and integrate these efforts from a total-Army perspective. The WSSPR Program will help the Army to identify and fill 
gaps, eliminate redundancies, and resolve differences in operating concepts. The result will be accelerated implementation and more efficient use of resources.

To facilitate development of the common vision for platform-focused logistics processes, the WSSPR Program is developing a comprehensive operational architecture for generating, capturing, moving, storing and using platform-based readiness data. A preliminary version of this architecture has been developed. USALIA has initiated an overlap/gap analysis to identify coordination points and recommend efforts needed to close the gaps. A host of things will have to be synchronized to implement the next-generation logistics processes - operating concepts, logistics doctrine, business processes, data schemas, interface standards, etc. We anticipate that the overlap/gap analysis will identify a number of places in the architecture where current efforts are not working toward a common vision. Architecture working groups will be convened, involving key stakeholders to work these issues. WSSPR will be the catalyst for resolving these conflicting views.

\section{References}

[1] CEAC. Economic Analysis Manual. U.S. Army Cost and Economic Analysis Center. Department of the Army, July 1995.

[2] Moore, JL (1995) Cost Benefit Analysis: Issues in its use for regulation. Congressional Report Service Report to Congress, 95-760ENR.

[3] GAO Report to Congress: "M1 Tanks: Status of the Proposed Overhaul Program". Report of the General Accounting Office (GAO/NSIAD-96-100), US General Accounting Office, Gaithersburg, 1996.

[4] Collinge, K, and K. Schoff. TEXMAS- An expert system of gas turbine engine diagnosis and more. SAE Technical Paper 871737. Aerospace Technology Conference, Long Beach CA Oct. 5-8, 1987.

[5] Greitzer, F. L., L. J. Kangas, K. M. Terrones, M. A. Maynard, B. W. Wilson, R. A. Pawlowski, D. R. Sisk, and N. B. Brown. Gas Turbine Engine Health Monitoring and Prognostics. SOLE '99 Symposium, August 31- September 2, 1999, Las Vegas, Nevada.

[6] Greitzer, F. L. and T.A. Ferryman. Predicting Remaining Life of Mechanical Systems. ASNE Intelligent Ship Symposium IV, April 2-3, 2001, Philadelphia, Pennsylvania.

[7] Greitzer, F. L., E. J. Stahlman, T. A. Ferryman, B. W. Wilson, L. J. Kangas, and D. R. Sisk. Development of a Framework for Predicting Life of Mechanical Systems: Life Extension Analysis and Prognostics (LEAP). SOLE '99 Symposium, August 31-September 2, 1999, Las Vegas, Nevada.

This research was performed by PNNL for the US Army Logistics Integration Agency under a Related Services Agreement with the U.S. Department of Energy, Contract DE-AC06-76RLO 1830. 